\title{
Survey on diabetic patients treated with insulin during the fasting month of Ramadan
}

This article was published in the following Dove Press journal: International Journal of General Medicine

\section{Mohamed Abid' \\ Mohamed Hsairi² \\ Mouna Elleuch' \\ Emna Ben Aissa ${ }^{3}$}

'Department of Endocrinology, Hedi Chaker Hospital, Sfax, ${ }^{2}$ Department of Epidemiology, Salah Azaiz Institute, Tunis, ${ }^{3}$ Medical Department SANOFI, Mégrine, Tunisia

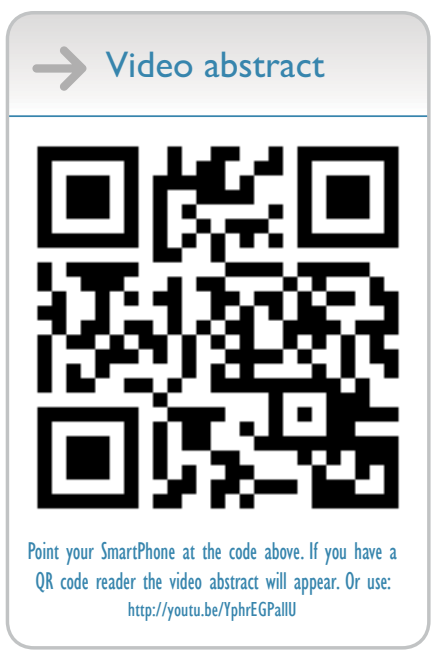

Correspondence: Mouna Elleuch Department of Endocrinology, Hedi Chaker Hospital, El Ain Road, Sfax 3029, Tunisia

Tel +21674242613

Email elleuch_mouna@yahoo.fr
Aim: To estimate the proportion of diabetic patients on insulin, who interrupt fasting during Ramadan, and describe the reported reasons of this interruption.

Design: This is a national observational survey of diabetic patients treated with insulin and fasting during the month of Ramadan 2013, proposed to all endocrinologists willing to participate. Consecutive patients were included until the required sample size, estimated at 498 patients, was obtained. Conducted among patients recruited by endocrinologists during the month following Ramadan 2013.

Results: Five hundred twenty-six (526) patients were included, of which 51 (9.7\%) had type 1 diabetes. The mean age was $36.8 \pm 11.6$ and $58.3 \pm 10.0$ years for type 1 and type 2 diabetes, respectively. The proportions of male subjects were $62.8 \%$ and $57.5 \%$ for type 1 and type 2 diabetes, respectively. The mean duration of diabetes was $11.0 \pm 8.8$ and $14.4 \pm 7.9$ years for type 1 and type 2 diabetes, respectively. During Ramadan, more than 55\% (54.9\% and 55.8\% for type 1 and type 2 diabetes, respectively) of patients were treated with insulin analog and over a third with mixed insulin. In this study population, $71.5 \%$ reported having fasted without interruption during the month of Ramadan. The average number of non-fasted days was $3.0 \pm$ 6.7 , mainly due to hypoglycemic episodes.

Conclusion: According to this observational survey conducted in Tunisia, most patients with diabetes treated with insulin (insulin in more than half of the cases) were able to fast without interruption during Ramadan.

Keywords: fasting, Ramadan, insulin, diabetes type 1, diabetes type 2

\section{Introduction}

Ramadan is a lunar-based month, with duration that varies between 29 and 30 days. Muslims who fast during Ramadan must abstain from eating, drinking, use of oral medications, and smoking from pre-dawn to after sunset; however, there are no restrictions on food or fluid intake between sunset and dawn. Most people consume two meals per day during this month - one after sunset and the other before dawn. ${ }^{1}$ Exemption from fasting during the month of Ramadan is authorized by Islam in case of acute or chronic disease, such as diabetes mellitus. However, most patients with diabetes are willing to fast during the month of Ramadan. ${ }^{2}$ The month of Ramadan is a challenge for the management of diabetes because of the fasting period, consequent changes in glycemic control, and, thereby, the potential hypo- and hyperglycemia of type 1 (T1DM) and type 2 (T2DM) diabetes mellitus that patients are exposed. According to a recent meta-analysis of Kul et al. ${ }^{3}$ submit your manuscript | www.dovepress.com 
- Patients with hypoglycemia unawareness, recent ketoacidosis, or hyperglycemic states, poor glycemic control, gestational diabetes, and advanced macrovascular complications are at high risk and should be advised not to fast.

- Patients with non-insulin-dependent diabetes on medication may have their dosages and timings reviewed.

- Insulin-dependent patients with diabetes on basal-bolus regimes are discouraged from fasting. If they still wish to fast, reducing their background insulin by $20 \%$ and altering the midday insulin can reduce complications.

Few studies have demonstrated the efficacy and safety of some therapeutic regimens with or without insulin in patients with type 2 and type 1 diabetes who fast during Ramadan, ${ }^{4,5}$ particularly for insulinized patients. Basal-plus and basalbolus regimes using rapid and long-acting insulin analogs are recommended. ${ }^{1}$

Nevertheless, available information on patients who discontinue fasting are very limited, especially in those treated with insulin; moreover, data about fasting, its observance, and treatment changes among patients with diabetes treated with insulin are very scarce.

The aims of the current study were to have:

- an estimation of the proportion of diabetic patients treated by insulin who interrupted fasting during the month of Ramadan

- identification of reasons for interrupted fasting, including severe hypoglycemia and ketoacidosis coma**,

- an estimation of the mean total number of fasting days, and to describe the profile of this diabetic population and the treatment changes before, during, and after Ramadan.

\section{Methods}

\section{Patients}

RAMADAN 3 is an observational survey of Tunisian patients with diabetes treated with insulin and fasting during the month of Ramadan 2013. This non-interventional study (no action taken on treatment decisions) was proposed to all endocrinologists who were willing to participate.

\section{Data collection}

The survey included only one visit in the month after Ramadan, during which the physician performed the consultation with usual examinations without introducing any changes in his usual clinical daily practices. Data were collected via a case report form (CRF) through a structured interview of the patient. The investigator was to report to the sponsor any adverse events suspected to be related to Sanofi products, and follow the usual reporting rules for non-Sanofi drugs.

All consecutive patients 18 years or older with diabetes who chose to fast during the month of Ramadan and were treated with insulin were included in this study. Patients were treated with any insulin available on the Tunisian market. Insulin analogs included insulin glargine, insulin detemir, insulin aspart, lispro, and glulisine. The premixed insulins used were Novomix 30 and Mixtard, and the human insulins used were intermediate insulin and rapid insulin. Patients with diabetes treated only by oral antidiabetic drugs (OADs), those who refused to consent to the use of the data, or those who participated simultaneously in another clinical study were excluded from this study.

Severe hypoglycemia was defined by the American Diabetes Association (ADA) as an event requiring assistance of another person to actively administer carbohydrates, glucagon, or take other corrective actions. Plasma glucose concentrations may not be available during an event, but neurological recovery following the return of plasma glucose to normal is considered sufficient evidence that the event was induced by a low plasma glucose concentration.

Diabetic ketoacidosis (DKA) was defined as hyperglycemia leading to hospitalization.

\section{Statistical analysis}

The primary analysis described the proportion of diabetic patients who stopped fasting during the month of Ramadan and the average number of days fasted. The secondary analysis described the study variables related to: demographic and economic characteristics of patients; the medico-surgical history; the last glycated hemoglobin (HbAlc) value; the practice of self-monitoring blood glucose during Ramadan; diabetes treatment before, during, and after the month of Ramadan, and changes to these treatments. The secondary analysis assessed reasons and moments of interruption of fasting as well as the occurrence of adverse events during Ramadan and their severity, especially hypoglycemia (during fasting or nocturnal severe hypoglycemia) and ketotic complications.

All continuous data were expressed as mean $\pm \mathrm{SD}$, and percentages were calculated for categorical variables. Comparison of percentages was performed by using chi-square, Fisher's exact, and Mac Nemar tests for paired series. Comparison of means was performed using the Student $t$-test and the analysis of variance test. Logistic regression model was conducted to identify factors associated to no interruption of fasting during Ramadan, while adjusting confounding factors. 
Two-tailed $p$ values $<0.05$ were accepted as significant. STATA software was used to conduct statistical analysis.

\section{Results \\ Baseline sociodemographic and clinical characteristics of study population}

This study included 526 patients with diabetes from 64 centers in both public and private health sectors, representing different areas of Tunisia.

The mean \pm SD age was $36.8 \pm 11.6$ years for type 1 diabetes, and $58.3 \pm 10.0$ years for type 2 diabetes; $62.8 \%$ and $57.5 \%$ of the study population were male in type 1 and type 2 diabetes groups, respectively. In type 1 and type 2 diabetes groups, respectively, the mean \pm SD of duration of diabetes was $11.0 \pm 8.8$ years and $14.4 \pm 7.9$ years and that for body mass index (BMI) was $25.2 \pm 4.3 \mathrm{~kg} / \mathrm{m}^{2}$ and 29.1 $\pm 5.0 \mathrm{~kg} / \mathrm{m}^{2}$. According to WHO BMI classification, in type 1 and type 2 diabetes groups, respectively, 8.3\% and 33.3\% were obese whereas the proportion of those overweight was $45.8 \%$ and $51.7 \%$ (Table 1 ).

\section{Fasting without interruption}

Of all included patients, $71.5 \%(67.6 \%-75.4 \%)$ reported having fasted without interruption during the month of Ramadan 2013. For patients who broke the fast, temporarily

Table I Baseline sociodemographic and clinical characteristics of study population, according to diabetes type

\begin{tabular}{|c|c|c|}
\hline $\begin{array}{l}\text { Characteristics of study } \\
\text { population }\end{array}$ & $\begin{array}{l}\text { Diabetes } \\
\text { type I }\end{array}$ & $\begin{array}{l}\text { Diabetes } \\
\text { type } 2\end{array}$ \\
\hline$n(\%)$ & $51(9.7)$ & $475(90.3)$ \\
\hline Age (years) & $36.8 \pm 11.6$ & $58.3 \pm 10.0$ \\
\hline \multicolumn{3}{|l|}{ Sex (\%) } \\
\hline Male & $32(62.8)$ & $272(57.5)$ \\
\hline Female & $19(37.3)$ & $201(42.5)$ \\
\hline \multicolumn{3}{|l|}{ Residence area (\%) } \\
\hline Urban & $45(88.2)$ & 431 (9I.3) \\
\hline Rural & $6(11.8)$ & $4 \mid(8.7)$ \\
\hline \multicolumn{3}{|l|}{ Missing data $=I$} \\
\hline \multicolumn{3}{|l|}{ Education level (\%) } \\
\hline Illiterate & I (2.0) & $64(13.6)$ \\
\hline Primary & $6(11.8)$ & II4 (24.2) \\
\hline Secondary & $28(54.9)$ & $170(36.0)$ \\
\hline University & $16(31.4)$ & $124(26.3)$ \\
\hline \multicolumn{3}{|l|}{ Missing data $=1$} \\
\hline Duration of diabetes (years) & $11.0 \pm 8.8$ & $14.4 \pm 7.9$ \\
\hline \multicolumn{3}{|l|}{ Body mass index $\left(\mathrm{kg} / \mathrm{m}^{2}\right)$} \\
\hline$<25$ & $22(45.8)$ & $68(15.1)$ \\
\hline $25-30$ & $22(45.8)$ & $233(5 \mid .7)$ \\
\hline$\geq 30$ & $4(8.3)$ & $150(33.3)$ \\
\hline
\end{tabular}

International Journal of General Medicine 2018:I I or permanently, the mean \pm SD number of non-fasted days was $3.0 \pm 6.7$ whereas the median approached 0 .

\section{Factors associated with fasting without interruption}

Table 2 summarizes factors associated with fasting during Ramadan without interruption. On multivariate analysis using a logistic model, no-interruption fasting was significantly more frequent in patients with type 2 diabetes $(\mathrm{OR}=1.969$ [1.043-3.716]; $p=0.036)$ and among male patients (OR = 1.677 [1.115-2.522]; $p=0.013$ ), with a significant trend for patients living in urban areas compared to those living in rural areas $(\mathrm{OR}=1.73$ [0.898-3.332]; $p=0.10)$, for patients with high level of education (university) compared those not in school or primary level $(\mathrm{OR}=1.756$ [0.998-3.089]; $p=0.05)$, and also for patients treated with insulin analogs compared with patients who did not receive it $(\mathrm{OR}=1.442$ [0.960-2.167]; $p=0.07)$. However, living with family was not associated with fasting without interruption (Table 3).

The two main reasons for fasting interruption during Ramadan 2013were the occurrence of hypoglycemia, particularly during the first week of Ramadan (63.1\%) and physician decision ( $18 \%$ in the first 2 weeks of Ramadan) Figure 1.

\section{Hypoglycemia episodes}

Of the patients interviewed, $20.3 \%$ reported having experienced episodes of hypoglycemia during the month before Ramadan and 23.4\% during the month of Ramadan. In fact, the mean number of hypoglycemic episodes increased during Ramadan in patients with type 2 diabetes, whereas it decreased in patients with type 1 diabetes. For all patients, the mean \pm SD number of reported hypoglycemia episodes, taking all severity levels together, did not change significantly from before to during Ramadan periods, ranging from 0.58 \pm 1.89 and $0.65 \pm 1.69$ episodes, respectively, per patient per month. The mean number of severe hypoglycemia episodes ranged between 0.04 and 0.07 episodes per patient per month, respectively, before and during Ramadan; during Ramadan, as compared to the month before Ramadan, the mean number of severe hypoglycemia episodes significantly decreased in patients with type 1 diabetes ( 0.00 vs 0.22 episode; $p=0.03)$ in contrast to those with type 2 diabetes, where the mean number of severe hypoglycemia episodes increased ( $0.07 \mathrm{vs}$ 0.03 episodes; $p=0.03$; Table 2 ).

Among the 526 patients included, only two instances of ketoacidosis coma were reported during Ramadan (0.4\%), and both patients had T1DM. 


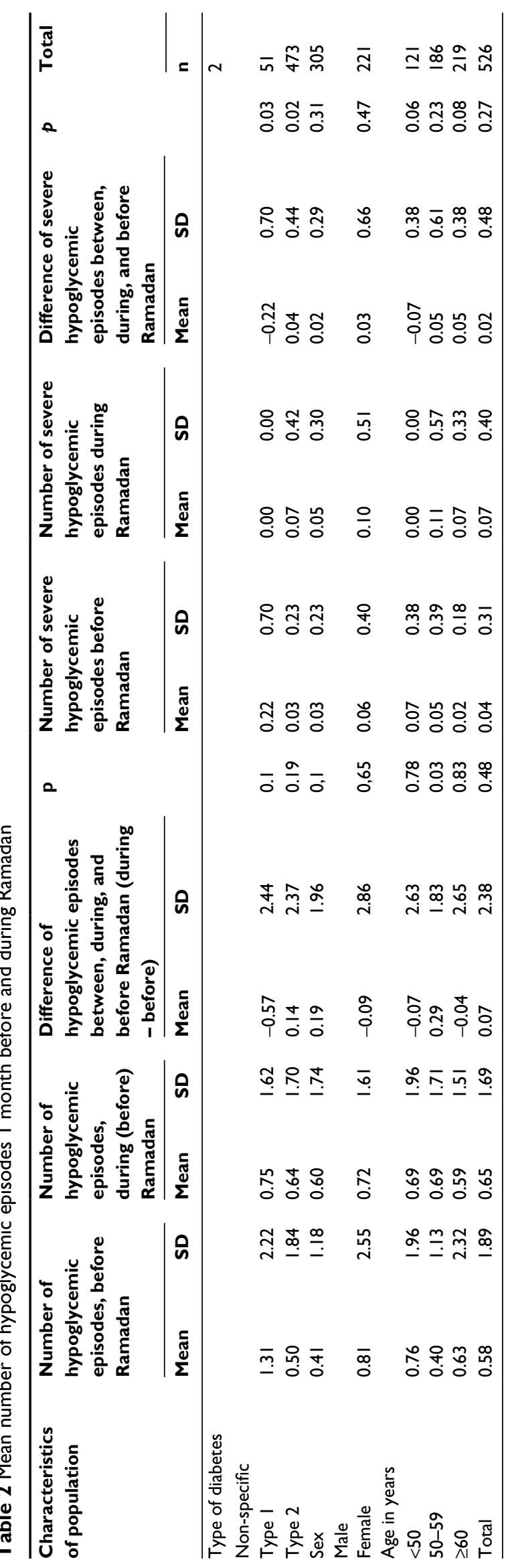

\section{Treatment changes}

With regard to changes in treatment, before Ramadan, basal insulin analogs were used in $54.9 \%$ and $55.2 \%$ of patients with T1DM and T2DM, respectively, followed by intermediate insulin (respectively, $33.3 \%$ and $35.5 \%$ ), and premixed was used only in $11.8 \%$ and $9.9 \%$, respectively. During Ramadan, the most common therapy was basal insulin analogs (for $54.9 \%$ and $55.8 \%$ of patients with type 1 and type 2 diabetes, respectively), followed by mixed insulin (35.3\% and $38.9 \%$ of patients with type 1 and type 2 diabetes, respectively) and intermediate insulin $(9.8 \%$ and $9.1 \%$ of patients with type 1 and type 2 diabetes, respectively; Figures 2 and 3). The use of basal insulin analogs remains unchanged, in contrast to the use of mixed insulin, which increased, and that of intermediate insulin, which decreased, during Ramadan.

\section{Diabetes biomarkers}

Before Ramadan, mean fasting plasma glucose (FPG) was $2.0 \mathrm{~g} / \mathrm{L}$ and $1.6 \mathrm{~g} / \mathrm{L}$ and mean $\mathrm{HbA} 1 \mathrm{c}$ was $9 \%$ and $8.6 \%$ in patients with type 1 and type 2 diabetes, respectively. Among subjects with normal values of FPG $(<1.27 \mathrm{~g} / \mathrm{L})$ and $\mathrm{HbA} 1 \mathrm{c}$ ( $<7 \%$ ), no significant changes were observed before, during, or after Ramadan (Table 4).

\section{Self-monitoring of blood glucose}

No significant difference was evident on comparing the proportion of the study sample that practiced self-monitoring of blood glucose during Ramadan in type 1 and type 2 diabetes ( $72.5 \%$ vs $64.3 \%$, respectively; $p=0.28$ ). However, the mean \pm SD number of self-monitoring checks of blood glucose per day was significantly higher among patients with type 1 diabetes $(2.4 \pm 1.5$ vs $1.6 \pm 0.9$ for patients with type 1 and type 2 diabetes, respectively; $p<0.001$ ). The mean number of self-measurement blood glucose checks per week during Ramadan was $4.5 \pm 4.6$ and $2.9 \pm 2.4$ in type 1 and type 2 diabetes, respectively $(p<0,007)$.

\section{Discussion}

This cross-sectional observational study of 526 patients with diabetes treated with insulin in the fasting state during the month of Ramadan has revealed that $71.5 \%$ of patients reported having fasted without interruption during the month of Ramadan in 2013. Multivariate analysis suggests that the main factors associated with fasting without interruption, after adjusting for confounding factors, were type 2 diabetes and male sex, with a trend for patients living in urban areas compared to those living in rural areas, for patients with high level - compared to those not in school or with primary level- 
Table 3 Factors associated with fasting during Ramadan without interruption: multivariate analysis using logistic model

\begin{tabular}{llll}
\hline Estimated odds ratios & & & \\
\hline Effect & Odds ratio & $\mathbf{9 5 \% ~ C o n f i d e n c e ~ l i m i t s ~ o f ~ o d d s ~ r a t i o ~}$ & P \\
\hline Type 2 vs type I DM & 1.969 & $(1.043-3.716)$ & 0.0367 \\
Male vs female & 1.677 & $(1.115-2.522)$ & 0.0131 \\
Urban vs rural & 1.730 & $(0.898-3.332)$ & 0.1011 \\
Secondary vs illiterate/primary & 1.309 & $(0.813-2.108)$ & 0.2675 \\
University level vs illiterate/primary level & 1.756 & $(0.998-3.089)$ & 0.0507 \\
Living with family vs living alone & 1.779 & $(0.728-4.349)$ & 0.2067 \\
Insulin analog & 1.442 & $(0.960-2.167)$ & 0.07 \\
\hline
\end{tabular}

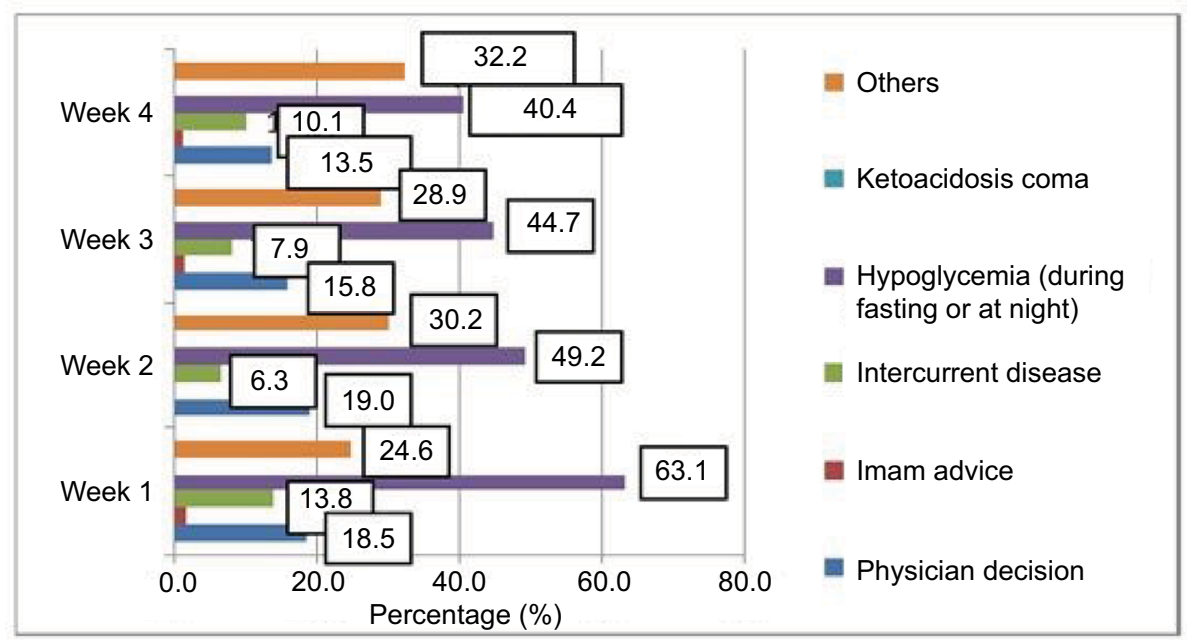

Figure I Reasons for fasting interruption during Ramadan 2013.

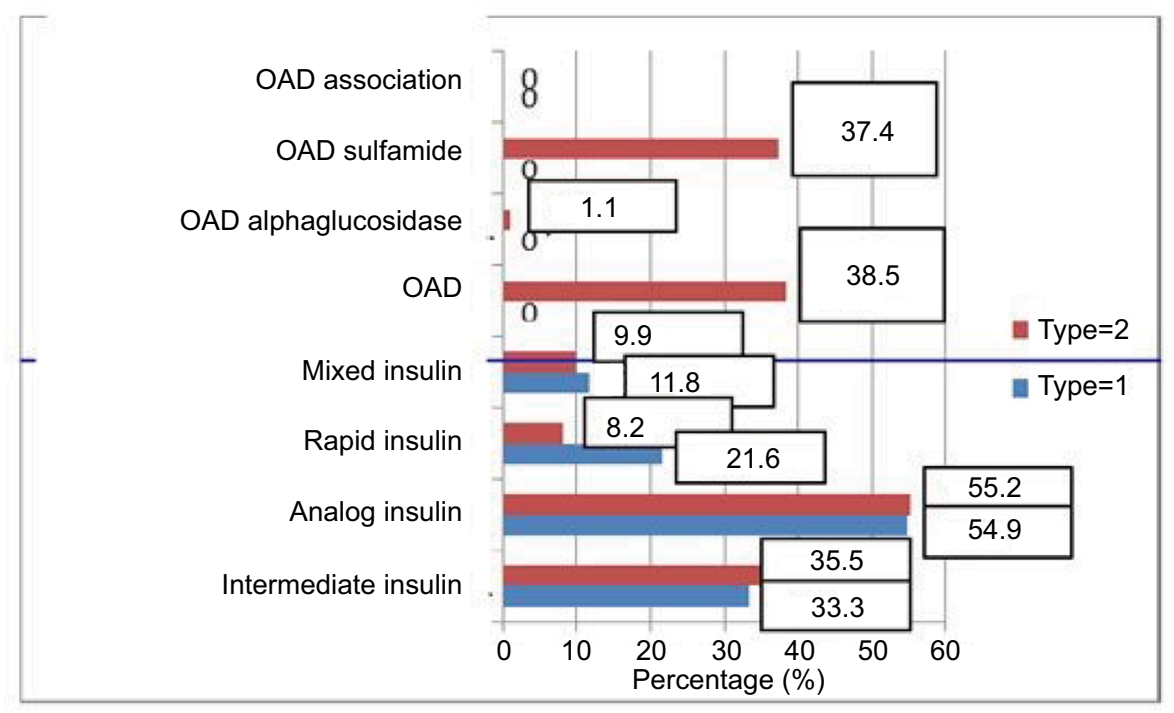

Figure 2 Treatment before Ramadan.

Abbreviation: OAD, oral anti diabetic.

of education (university), and also for patients treated with insulin analogs. The mean number of days not fasted was 3.0 \pm 6.7 days. The main reason for interruption of fasting during Ramadan was hypoglycemia episodes and physician decision.
Self-monitoring of blood glucose was relatively frequent (undertaken by $72.5 \%$ of patients with type 1 and $64.0 \%$ of patients with type 2 diabetes), but it needs to be improved as by number of this practice per day or per week. 


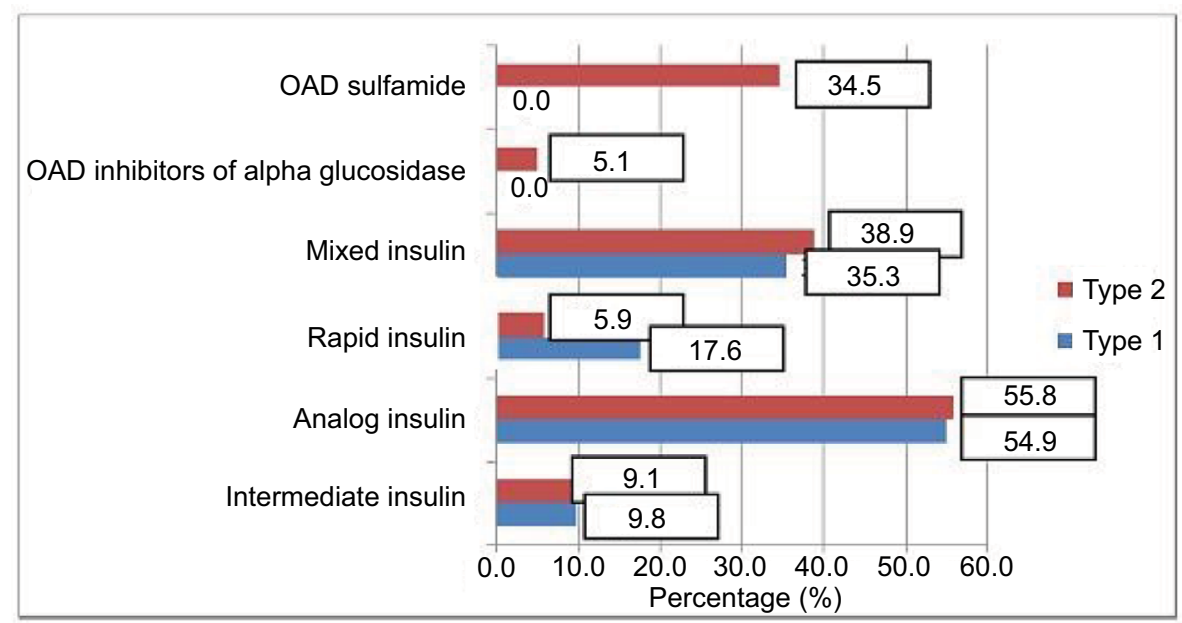

Figure 3 Treatment during Ramadan.

Abbreviation: OAD, oral anti diabetic.

Table 4 Proportion of normal values of fasting plasma glucose and HbAlc, before, during, or after Ramadan

\begin{tabular}{|c|c|c|c|}
\hline & \multicolumn{2}{|c|}{ Type of diabetes } & \multirow[t]{2}{*}{$P$ (type I vs type 2$)$} \\
\hline & $\begin{array}{l}\text { Type I } \\
\text { n (\%) }\end{array}$ & $\begin{array}{l}\text { Type } 2 \\
\text { n (\%) }\end{array}$ & \\
\hline Fasting plasma glucose $<1.27 \mathrm{~g} / \mathrm{L}$, before Ramadan & $7(25.0)$ & $128(33.2)$ & 0.36 \\
\hline Fasting plasma glucose $<1.27 \mathrm{~g} / \mathrm{L}$, during or after Ramadan & $8(20.0)$ & $118(27.4)$ & 0.3 \\
\hline$P$ (before vs during or after Ramadan) & 0.31 & 0.19 & \\
\hline $\mathrm{Hb}$ IAc $<7 \%$ before Ramadan & $5(18.5)$ & $51(14.3)$ & 0.55 \\
\hline $\mathrm{Hb} \mid \mathrm{Ac}<7 \%$ during or after Ramadan & $4(10.3)$ & $54(14.8)$ & 0.43 \\
\hline$P$ (before vs during or after Ramadan) & 0.41 & 0.74 & \\
\hline
\end{tabular}

Despite religious and medical recommendations, clearly stated as in other Muslim countries, specifying that people with high risk do not have to fast, ${ }^{6}$ many patients with diabetes in Tunisia insist on fasting during Ramadan. This attitude was also reported in Algerian patients with diabetes. ${ }^{7}$ On the other hand, most insulin-treated patients (71.5\%) fasted without interruption. This proportion was closely similar (70.4\%) to a survey conducted in Benghazi (Libya). ${ }^{7}$ For the remaining patients who interrupted their fast, the main reason was the occurrence of hypoglycemia episodes. In the present study, $23.4 \%$ of all patients reported at least one hypoglycemic episode during Ramadan 2013, whereas only two patients reported instances of ketoacidosis coma. In Benghazi's survey $^{7}$, the frequency of hypoglycemia as a main reason of breaking the fast was higher (43.4\%), and the proportion of severe hyperglycemia for the same reason was much higher in comparison to that in the present study (27\%).

In a Pakistan study of patients with type 1 and type 2 diabetes, $33.33 \%$ and $48 \%$, respectively, discontinued their fast when they experienced symptoms of hypoglycemia. ${ }^{8}$ Overall, symptomatic hypoglycemia was observed in $23.7 \%$ of patients (in $35.29 \%$ and $23.18 \%$ of patients with type 1 and type 2 diabetes, respectively).

Loke et al in their prospective cohort study on the effect of various risk factors of hypoglycemia in diabetics who fast during Ramadan reported the rate of hypoglycemia to be 1.6 times higher during the fasting period, compared with non-fasting periods. ${ }^{9}$

Moreover, hypoglycemia remains an infrequent cause of death in this group of patients; patients with diabetes should be educated about this very serious event, especially during fasting.

The proportion of patients who interrupted fasting for at least 1 day was $28.5 \%(24.6 \%-32.4 \%)$ in the present study; this was higher than the proportion observed in 2009 $(17.5 \%) .{ }^{10}$ The patient selection process of the two studies was quite similar, even if, in the previous study, patients were not necessarily treated with insulin, the actual results could probably be explained, at least in part, by the difference in climatic conditions between the two periods (the temperature was higher in 2013), associated with a higher number of hours of fasting per day than in 2009. 
In this study, there was a trend for the association of insulin analogs with complete fasting during Ramadan. Cesur et $\mathrm{al}^{11}$ reported that long-acting insulin, such as glargine, should be given at Iftar to avoid potential hypoglycemia during daytime fasting. Surprisingly, and despite international guidance, this study show that treatment changes during Ramadan appeared to favor premixed insulin more than analogs, suggesting that further training on guidelines should be proposed.

The principal limitations of the present study are the observational design of this study and the inclusion of patients treated by endocrinologists, from across the country in both public and private sectors. Nevertheless, the selection of investigators was not randomly done using a sampling frame of physicians treating diabetes; therefore, it could not be qualified as a population-based study. In addition, the observed results can be generalized only to patients with diabetes fulfilling the inclusion and exclusion criteria defined for the present study.

\section{Conclusion}

Ensuring good control of plasma glucose during the fasting month of Ramadan is a challenge for both physicians and patients. This cross-sectional observational study conducted in Tunisia showed that fasting without interruption during Ramadan was common ( $>70 \%$ ) among patients with diabetes who were treated by insulin. The mean number of days not fasted was $3.0 \pm 6.7$ days. The main observed factors associated with fasting without interruption were diabetes type 2 and male sex. The main reason for interruption of fasting during Ramadan was the occurrence of episodes of hypoglycemia. Insulin analogs were used in more than half of the patients participating in the study.

The authors confirm that this study was approved by Ethics committee of Hedi Chaker Hospital in 17/08/2013, and all participants provided written informed consent.

\section{Acknowledgments}

The authors acknowledge SANOFI laboratory for supporting this study and all the investigators: Borni Zidi, Haroun Ouertani, Amel Jaidane, Bassem Louzir, Faida Ajili, Myrvet Kammoun, Yamina Fourti, Samia Sellami, Leila Cheraga, Kamel Ben Rebia, Awatef Mekawer, Jazia Hamzaoui, Awatef Marouani Ousleti, Bochra Fetouhi, Ines Khochtali, Fatma Haj Youssef, Dorsaf Skhiri, Riadh Miladi, Sameh Fradi, Habib
Sfar, Meriem Ferchichi, Ilhem Ardhaoui, Amel Maaroufi, Nada Dellel Youssef, Ibtissem Jaballah, Salambo Ernez, Larbi Chaieb, Molka Chadly Chaieb, Maha Kacem, Jamil Belaid, Mounir Garali, Adnene Derbel, Jamel Souilem, Lotfi Cherif, Maria Hadded, Fatma Boussema, Fethi Derouiche, Faycal Jait, Said Chammakhi, Meriem Ennabli Nawer, Basma Cheour, Hichem Terzi, and Mohamed Aissaoui.

\section{Disclosure}

Dr Abid reports receiving payment as principal investigator, and Dr Hsairi reports receiving payment as the biostatistician for this study. Dr Ben Aissa participated in writing the manuscript as membre of medical department in SANOFI Tunisia Morroco. The authors report no other conflicts of interest in this work.

\section{References}

1. Al-Arouj M, Assaad-Khalil S, Buse J, et al. Recommendations for management of diabetes during Ramadan. Diabetes Care. 2010;33(8):1895-1902.

2. Salti I, Bénard E, Detournay B; EPIDIAR Study Group. A populationbased study of diabetes and its characteristics during the fasting month of Ramadan in 13 countries: results of the epidemiology of diabetes and Ramadan 1422/2001 (EPIDIAR) study. Diabetes Care. 2004;27(10):2306-2311.

3. Kul S, Savaş E, Öztürk ZA, Karadağ G. Does Ramadan fasting alter body weight and blood lipids and fasting blood glucose in a healthy population? A meta-analysis. J Relig Health. 2014;53(3):929-942.

4. Mucha G T, Merkel S, Thomas W, Bantle JP. Fasting and insulin glargine in individuals with type 1 diabetes. Diabetes Care. 2004;27(5):1209-1210.

5. Salti I; Diabetes and Ramadan Study Group. Efficacy and safety of insulin glargine and glimepiride in subjects with Type 2 diabetes before, during and after the period of fasting in Ramadan. Diabet Med. 2009;26(12):1255-1261.

6. Chentli F, Azzoug S, Amani Mel A, Elgradechi A. Diabetes mellitus and Ramadan in Algeria. Indian J Endocrinol Metab. 2013;17(Suppl 1): S295-S298.

7. Elmehdawi RR, Mukhtad NA, Allaghi NI, Elmajberi SJ. Fasting of Ramadan in peoples with diabetes in Benghazi, Libya: an exploratory study. Libyan J Med. 2010;5:5036-5040.

8. Ahmedani MY, Alvi SF, Haque MS, Fawwad A, Basit A. Implementation of Ramadan-specific diabetes management recommendations: a multicentered prospective study from Pakistan. J Diabetes Metab Disord. 2014;13(1):37.

9. Loke SC, Rahim KF, Kanesvaran R, Wong TW. A prospective cohort study on the effect of various risk factors on hypoglycemia in diabetes who fast during Ramadan. Med J Malaysia. 2010;65(1):3-6.

10. Mnif F, Slama CB, Chaieb L, Blouza S, Hsairi M, Abid M. Observational study of the Tunisian diabetic patients' profile during the fasting of the holy month of Ramadan. J Endocrinol Diab. 2016;3(4):1-8.

11. Cesur M, Corapcioglu D, Gursoy A, et al. A comparison of glycemic effects of glimepiride, repaglinide, and insulin glargine in type 2 diabetes mellitus during Ramadan fasting. Diabetes Res Clin Pract. 2007;75(2):141-147. 


\section{Publish your work in this journal}

The International Journal of General Medicine is an international, peer-reviewed open-access journal that focuses on general and internal medicine, pathogenesis, epidemiology, diagnosis, monitoring and treatment protocols. The journal is characterized by the rapid reporting of reviews, original research and clinical studies across all disease areas.
The manuscript management system is completely online and includes a very quick and fair peer-review system, which is all easy to use. Visit http://www.dovepress.com/testimonials.php to read real quotes from published authors.

Submit your manuscript here: https://www.dovepress.com/international-journal-of-general-medicine-journal 